\title{
Study on the transference phenomenon of the skeleton-dense structure cement stablized aggregate
}

\author{
Zhou Hao ${ }^{1,2, a}$, Zhang Guixia ${ }^{3, b}$, Zhao Quanman ${ }^{1, c}$, Yang Ziqiao ${ }^{1, d}$
}

1. School of Transportation Engineering, Shandong Jianzhu University, Shandong Jinan, 250101

2.Key Laboratory for Special Area Highway Engineering of Ministry of Education, Chang'an University, Shaanxi Xi'an,710064

3.Zhengzhou University of Aeronautics, School of Civil Engineering, Henan Zhengzhou 450015

azhouhao1983@126.com, bliuletian666@163.com, 'zhaoquanman11@163.com, d yangziqiao520@126.com

Keywords: skeleton-dense structure; transference phenomenon; gradation; mechanical strength; fatigue property

Abstract: Skeleton-dense cement treated stone (STCB) may occur segregation; a laboratory test was carried out to study a specific segregation which could be named migration temporarily in this paper. Two kinds of STCB were tested, two impact factors were identified, and the influence of migration on mechanical property and fatigue performances were studied. The results show that the mixture with coarse grading or high water content was easy to migrate. After migration, compressive strength may reduce a little, while the flexural strength will increase significantly; the material will be more sensitive to fatigue load, but the actual baring capacity may be improved; the initial dynamic modulus value of the migrated STCB is bigger but the decay rate is higher.

\section{Problem Posing}

Skeleton-dense cement treated stone has advantage of high strength, small shrinkage, erosion resistant $^{[1]}$, but the unreasonable gradation may make mixture segregate, the fine aggregate and the binder may move downward under indoor vibration compaction condition, this phenomenon is named as transference in this paper temporarily. And this migration phenomenon has influence on the material performance.

The paper implement compressive strength and flexural test on three gradations skeleton-dense cement treated stone, with the 5\% cement. The three indoor vibration compaction methods is used to determined the best water content and maximum dry density and forming and then the unconfined compressive strength and flexural strength of 90 days are tested after corresponding curing period, The gradation and mechanical test results are shown in the following two figures:
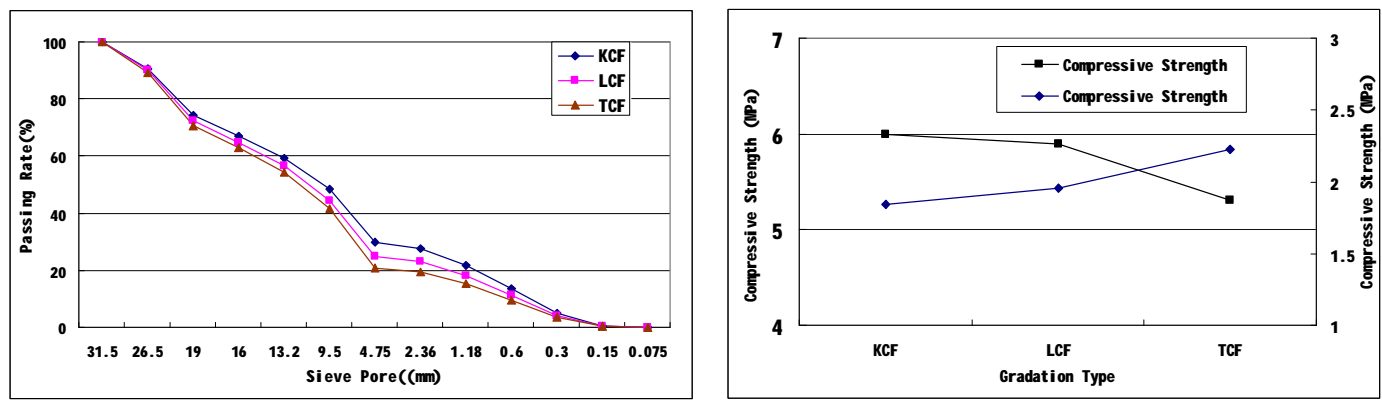

Figure 1 Gradations of STCB

Figure 2 Compressive Strength and Flexural Strength of STCB

The rule of flexural strength and the rule of seven days unconfined compressive strength were 
opposite, and they run counter to conventional rule, the strength of tight pack skeleton cement stable stone increase abnormally. After observation, the material is relatively close-grained, upper fine aggregate in it has little content, porosity is very big and lower fine aggregate has high content. It may produce segregation phenomenon, then it needs further study.

The flexural strength of tight compacted frame (TCF) cement stabilized stone is significant bigger that of others, which is contrary to the rule of 7-day unconfined compressive strength and against to the general rule. Careful observation shows that the upper layer of specimen contains little fine material, and the porosity is very big, the lower layer of specimen contains much more fine material, and further study is needed.

\section{Influence Factors of Migration}

Two factors, the gradation and the water content, are researched. The mixture composition is shown in table 1 . The specimen is mixed and charged twice and compacted one time. Half of specimen is mixed, charged, hand tamped and then the other half mixture is mixed and charged, and the whole specimen is compacted. After compaction, the fine aggregate and water content of upper and lower half of the specimen are measured separately. The gradations of mixtures are evaluated by the passing rate of $9.5 \mathrm{~mm} 、 2.36 \mathrm{~mm} 、 0.3 \mathrm{~mm}$ sieve pore.

Four groups of beam mixture ratio as follows:

The first group: knock compacted frame $(\mathrm{KCF})$ gradation, $5 \%$ cement, $4.5 \%$ water;

The second group: knock compacted frame (KCF) gradation, $5 \%$ cement, $6.0 \%$ water;

The third group: tight compacted frame (TCF) gradation, $5 \%$ cement, $4.5 \%$ water;

The fourth group: tight compacted frame (TCF) gradation, $5 \%$ cement, 5.5\% water.

Gradations after compact test are listed in table 4.1.

Table 1 Key Sieve Pore Passing Rate of Original Gradation

\begin{tabular}{|c|c|c|c|c|}
\hline Sieve Pore Gradation[mm] & 31.5 & 9.5 & 2.36 & 0.3 \\
\hline Knock Compacted Frame [\%] & 100.0 & 48.7 & 28.4 & 5.1 \\
\hline $\begin{array}{c}\text { Tight Compacted Frame } \\
\text { Gradation[\%] }\end{array}$ & 100.0 & 40.5 & 18.0 & 3.2 \\
\hline
\end{tabular}

Variation of the passing rate and the water content are shown as figure 3 and figure 4.

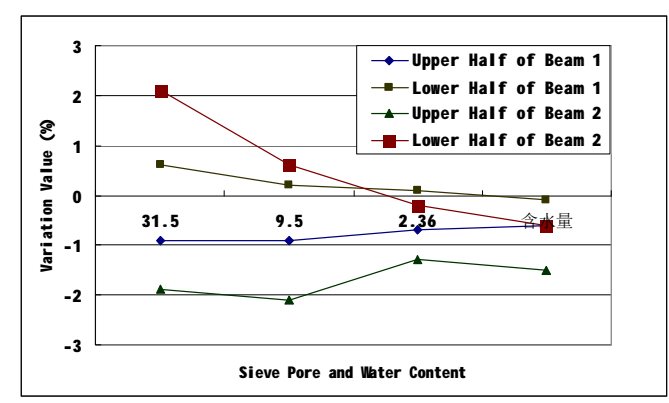

Figure 3Transference of KCF Gradation

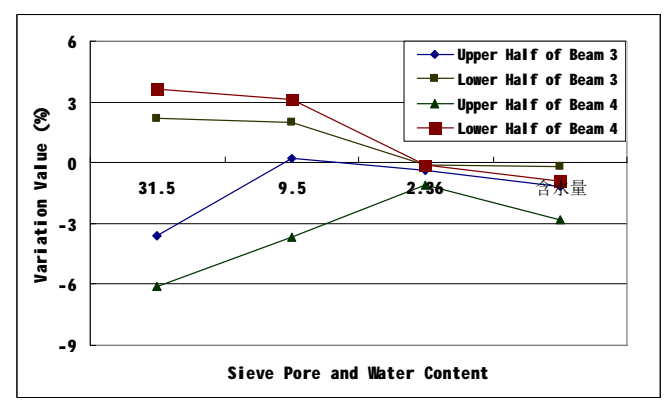

Figure 4 Transference of TCF Gradation

The passing rates of the upper half and lower half of the spices separately decrease and increase, nearly with similar extent, this is the result of the fine aggregate transfer. The fine aggregate passing rate and water content of the whole specimen is decreased compare with the initial mixture composition. Because there is some cement slurry loss in the forming process, and some fine aggregate also loss in water sieve process.

From the two figures above, the following conclusions can be get: 
1 Migration of water is influenced by water content and gradation, especially the water content. Water is transfer seriously if the water content is high, and the coarse gradation can make the transference server.

2 Migration of fine aggregate $(0.3 \mathrm{~mm}-2.36 \mathrm{~mm})$ is influenced by water content and gradation, especially the gradation. Fine aggregate is easy to transfer if the gradation is coarse, and the higher water content can increase the degree of migration.

3 The test failed to measure the cement transfer phenomena directly. But the degree of cement migration should between that of $0.075 \mathrm{~mm}-0.3 \mathrm{~mm}$ fine aggregate and water, and should be influenced by both the water content and the gradation.

Further observation shows that reduce of fine aggregate caused by migration generally occur in upper one third of specimen thickness, and the rest two-thirds of specimen contains more fine aggregate. The fine aggregate is migrate from upper $1 / 3$ to lower $2 / 3$ of the specimen, not upper half to lower half, a little different from the experimental design.

The test has certain errors: (1) Some slurry, mainly contains the fine aggregate pass $1.18 \mathrm{~mm}$ sieve pore and the cement, may be lost while mixing materials or vibrate compacting specimen. (2) Error occurs during layered material taking. There are some aggregate in interface of upper and lower specimen, and it is difficult to determine which layer it belongs to. The experiment shows that if the content of fine aggregate in lower half is 1.5 times of that of upper half, and the water content of lower half of specimen is 1.7 times of that of upper half. It can be infer that the cement transference is similar as the fine aggregate and water, there is more slurry in the lower half of specimen and get higher tensile stress.

\section{Influence of the transference on the material properties}

\section{Mechanical strength}

According to the test in chapter 1 , the compressive strength of migrated materials may be slightly lower, but the flexural strength will be improved obviously. The reason is that after migration, the upper part of specimen is lack of binder, and is easy to broken under compress. The material mechanics shows that the upper beam is in pressured state, and the lower beam is in flexural tensile state during bending test ${ }^{[2]}$.

The lower half of migrated material contains more binder and has higher strength and the upper half is weak. But to cement base material, the compressive strength is more higher than the flexural strength ${ }^{[3]}$, therefore the strength decrease of the upper materials has little influence on the whole beam mechanical properties, and material finally to show high flexural strength finally.

\section{fatigue performance}

Semi-rigid asphalt pavement is the most important pavement structure in our country. In order to improve the fatigue properties of semi-rigid base materials which are the main bearing stratums of the road, the fatigue resistance strength is principal performance.

The pavement structure bears the sustained traffic loadings in service period, there will be micro fractures generated in semi-rigid material, and the base may fail if the loading stress exceed material strength ${ }^{[4]}$. The paper researched fatigue properties of the three mixtures mentioned in chapter $1^{[5-6]}$, at the same time, the strain of beam bottom surface center is also measured to study the dynamic modulus of semi-rigid material. 
Table 2 Results of Fatigue Test

\begin{tabular}{|c|c|c|c|c|}
\hline \multirow{2}{*}{ Type of Material } & \multicolumn{2}{|c|}{$\begin{array}{l}\text { Parameters of Regression Equation } \\
(\operatorname{lgN}=a+b S)\end{array}$} & \multirow{2}{*}{$\begin{array}{l}\text { Fatigue } \\
\text { Strength }\end{array}$} & \multirow{2}{*}{$\begin{array}{l}\text { Absolute } \\
\text { Fatigue } \\
\text { Strength } \\
(\mathrm{MPa})\end{array}$} \\
\hline & $\mathrm{a}$ & $\mathrm{b}$ & & \\
\hline $\mathrm{KCF}$ & 13.7974 & -13.8807 & 0.5617 & 1.1 \\
\hline $\mathrm{LCF}$ & 13.4852 & -13.6569 & 0.5481 & 1.011 \\
\hline TCF & 14.6881 & -15.6664 & 0.5546 & 1.232 \\
\hline
\end{tabular}

Deflection and strain of semi-rigid materials beam increase and the modulus decrease during fatigue test, which is the degradation process of material. The modulus degradation process can be divided into three stages ${ }^{[6]}$ : The first stage, the modulus degraded rapidly due to the internal defects of the specimen itself. The second stage, modulus deteriorates more slowly and has linear relationship with loading number. Deterioration range varies with stress level, the higher the stress level is, the greater the deterioration rate is. The third stage is destabilization damage stage. During this stage, modulus reduces rapidly and the specimens failed finally. The modulus at the beginning is defined as initial modulus and the modulus corresponding to the half of fatigue life is defined as effective modulus.

The fatigue equations of different materials shows that the transferred material has highest initial fatigue life value, but it is very sensitive to load increasing. The dynamic modulus study shows that the TCF cement stabilized stone has high initial dynamic modulus but low effective modulus. This phenomenon attribute to the composition characteristic of this mixture: the bottom of the specimen contains more cement, and has higher modulus. But the whole specimen is not dense, so the modulus of specimen decay quickly.

Table 3 Results of Dynamic Modulus Test

\begin{tabular}{|c|c|c|}
\hline Mixture Type & $\begin{array}{c}\text { Initial } \\
\text { Modulus[MPa] }\end{array}$ & $\begin{array}{c}\text { Effective } \\
\text { Modulus[MPa] }\end{array}$ \\
\hline Knock Compacted Frame & 24488 & 13121 \\
\hline Loose Compacted Frame & 28379 & 14017 \\
\hline Tight Compacted Frame & 31091 & 13474 \\
\hline
\end{tabular}

\section{Conclusion:}

1. The Skeleton-dense cement stone migration may occur in vibrate compaction, the fine aggregate, binder and the water may move downward, and the main influence factors are the gradation and the water content.

2. The compressive strength of migrate materials may be slightly lower, but the flexural strength will be improved obviously.

3. The fatigue equations of different materials shows that the migrate material has highest initial fatigue life value, but it is very sensitive to load increasing. The TCF cement stabilized stone has high initial dynamic modulus but low effective modulus.

\section{Acknowledgements}

This work was financially supported by the National Natural Science Foundation of China (No . 51608511) and the Shandong Jianzhu University Doctoral Foundation(No. 0000601523) 


\section{References}

[1]HU Li-qun. Research on Structural Characteristic and Component Design Methods for Semi-rigid Base Course Material[D]. Xi'an: Chang'an University, 2004

[2] LIU Hong-wen. Material Mechanics (third edition) [M].Higher Education Press, Beijin 140-149)

[3]Shen Aiqin. Cement and Cement Concrete[M]. People Transportation Publication, Beijin 2000 28-29

[4] YANG Qun, HUANG Xiaoming. An Analysis of Fatigue Design of Asphalt Base and Simi-rigid Base [J].Journal of Highway and Transportation Research and Development, 2001, 18(6): $5-9$.

[5]Jia Kan. Study on the Fatigue Performance of Semi-rigid Base Course Materials.[D]. Xi'an: Chang'an University, 2008.

[6] Lu Jianqing. Deterioration Laws of Semi-rigid base Modulus [D]. Xi'an: Chang'an University, 2007 